\title{
Interactions with host cells causes Neisseria meningitidis pili to become unglued
}

\author{
Adrienne Chen and H. Steven Seifert* \\ Department of Microbiology-Immunology, Northwestern University Feinberg School of Medicine, Chicago, IL, USA \\ *Correspondence: $h$-seifert@northwestern.edu
}

\section{A commentary on}

Posttranslational modification of pili upon cell contact triggers $N$. meningitidis dissemination

by Chamot-Rooke, J., Mikaty, G., Malosse, C., Soyer, M., Dumont, A., Gault, J., Imhaus, A. F., Martin, P., Trellet, M., Clary, G., Chafey, P., Camoin, L., Nilges, M., Nassif, X., and Dumenil, G. (2011). Science 331, 778-782.

Neisseria meningitidis is an obligate human commensal organism that usually resides within the nasopharynx. The first step in establishing colonization of the nasopharyngeal mucosal surface is adherence to epithelial cells via a number of bacterial surface structures. Type IV pili play an important role in mediating bacterial adherence to host cells, as isolates from both asymptomatic carriers and patients with meningococcal disease are found to be heavily piliated, and piliated bacteria attach more efficiently to epithelial cells than non-piliated isolates. Subsequent to attachment, bacteria multiply on the cell surface in tightly associated microcolonies, which are highly dynamic structures that grow, fuse, and are motile (Higashi et al., 2007), and from where it is thought bacteria eventually detach to either disseminate to new locations within the existing host (e.g., via crossing the epithelial layer to access the bloodstream and the meninges), or transmit to new hosts.

Type IV pili are long filamentous appendages containing multiple protein subunits, the major component of which is the main pilus subunit (pilin). Individual pili can aggregate to form bundles composed of 8-10 individual fibers, which act as coordinated retractable units that are capable of exerting nanonewton scale forces on the infected cell (Biais et al., 2008). The extent of pilus bundling appears to affect the degree of bacterial adherence to cells, as well as the propensity to grow in microcolonies (Marceau et al., 1995). Pilin subunits can be post-translationally modified by phosphoethanolamine (PE), phosphocholine (PC), phosphoglycerol (PG), and by O-linked glycosylation. Several serine residues within the N. meningitidis pilin, as well as pilin from the closely related $N$. gonorrhoeae, have been shown to undergo modification. Serine 63 is modified by O-linked glycosylation, serine 68 is modified by either PE or PC, and PG has been identified as a modification of serine 93 (Stimson et al., 1995, 1996; Forest et al., 1999; Hegge et al., 2004). These post-translational modifications in turn exert an influence on pilus morphology and pilus-mediated adherence to human cells, as loss of glycosylation increases $N$. meningitidis adherence (Marceau et al., 1998), and loss of the PE/ PC modification results in increased pilus bundling in N. gonorrhoeae, but does not affect adherence (Forest et al., 1999). The genes involved in mediating glycosylation and $\mathrm{PE} / \mathrm{PC}$ addition have been identified (Warren and Jennings, 2003; Hegge et al., 2004), but the enzyme responsible for PG addition was unknown.

Chamot-Rooke et al. (2011) identified a N. meningitidis gene which is upregulated several-fold upon host cell contact, and which is responsible for adding phosphoglycerol (PG) to pilin subunits at serine residue 93. Mutation of the pilin phosphotransferase B ( $p p t B)$ gene (NMV_0885), an ortholog of other phosphoglycerol transferases, resulted in a total loss of PG modification, and induction of a $p p t B$ gene under lac promoter control resulted in increased PG modification. Molecular modeling of the region surrounding serine 93 suggests that it carries a highly positive charge, which would be disturbed by the addition of a negatively charged PG group, which in turn was predicted to destabilize interactions between adjacent pilus fibers within a bundle. Consistent with this hypothesis, the induction of $\mathrm{PptB}$ expression and PG modification resulted in a decrease in pilus bundling, and a transition to expression of single pili. This decrease in bundling led to decreased bacterial aggregation, which was reversed when PG modification was abrogated by either deleting $p p t B$ or mutating the modified serine residue.

Alterations in the ability of N. meningitidis to form bundled pili and to adhere to host cells has implications for its ability to both grow in microcolonies on the infected cell surface, and its ability to detach from cells to mediate dissemination. PG modification did not appear to have an effect on either bacterial attachment or microcolony growth, but deletion of $p p t B$ did result in decreased bacterial detachment from epithelial cells in a laminar flow chamber, as well as decreased cellular invasion and migration across a monolayer.

These results suggest a scenario where $p p t B$ upregulation upon host cell contact triggers PG modification on pilin subunits, where the introduction of a destabilizing negative charge mediates disruption of pilus bundles and facilitates bacterial detachment from the microcolony (Figure 1). This intriguing finding raises a number of additional questions: (1) What is the mechanism of pilin modification? Where is PptB localized within the bacterial cell, and are the pilin subunits modified inside the cell and subsequently translocated across the pilus biogenesis machinery? Is pilus retraction involved in regulating glycerophosphorylation? (2) What are the signals regulating $p p t B$ expression? Does $p p t B$ induction result from direct cell contact or are there other signals from the host? Is there a spatial or temporal subset of bacteria in a microcolony that receive the signal from the host cell? Is $p p t B$ expression downregulated after bacterial detachment to allow the re-formation of pilus bundles? Is $p p t B$ only induced in certain host environments and/or tissues or is the transition from bundled to unbundled pili also important for crossing the bloodbrain barrier? (3) PptB is part of a regulon induced upon host cell contact that includes 

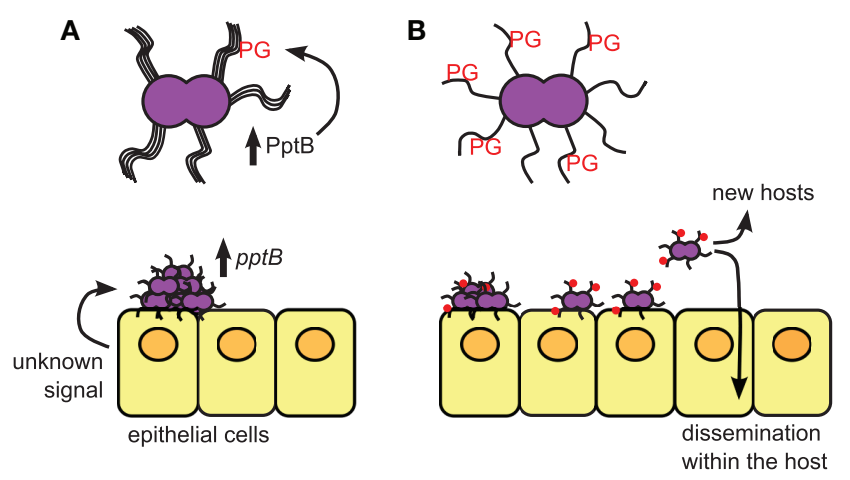

FIGURE 1 |The role of PptB in mediating meningococcal dissemination. (A) Bacteria growing on the epithelial cell surface in microcolonies are induced to express PptB after host cell contact, which induces addition of phosphoglycerol (PG) onto pilin subunits. (B) Bacteria whose pili have been PG-modified lose their aggregative properties due to loss of pilus bundling, and begin to detach from the microcolonies. Detached bacteria can then move to different sites within the same host, or be transmitted to new hosts.

other genes involved in adhesion such as pilC1 and $\operatorname{crg}$ A. How does $p$ ptB induction fit into the broader context of regulated pilus expression during infection? (4) Do the other pilin post-translational modifications contribute to this process? Both glycosylation and PE/PC modification on other residues can affect bacterial attachment and pilus bundling, therefore are these various modifications coordinately regulated during the course of infection? If so, is there an additive effect of the modifications or a hierarchy of effects?

A number of other bacteria also express type IV pili, including human pathogens such as Pseudomonas aeruginosa and enteropathogenic Escherichia coli. Posttranslational modification of other type IV pilus subunits has not been extensively characterized, thus it is an open question whether other pathogens that use type IV pili for attachment to host cell surfaces also employ similar mechanisms to regulate aspects of their pathogenicity. Regulated post-translational modification of any surface structures involved in mediating bacterial-host interactions could therefore provide an additional means by which bacteria fine-tune their physiology to best exploit the host environment in which they reside.

\section{ACKNOWLEDGMENTS}

Suggestions for improvement of the manuscript were provided by Mark Anderson and Carl Gunderson. Adrienne Chen was partially supported by American Heart Association fellowship 10POST2550017. H. Steven Seifert was partially supported by NIH grants R01 AI44239 And R37 AI33493.

\section{REFERENCES}

Biais, N., Ladoux, B., Higashi, D., So, M., and Sheetz, M. (2008). Cooperative retraction of bundled type IV pili enables nanonewton force generation. PLoS Biol. 6, e87. doi: 10.1371/journal.pbio.0060087

Chamot-Rooke, J., Mikaty, G., Malosse, C., Soyer, M., Dumont, A., Gault, J., Imhaus, A.F., Martin, P., Trellet, M., Clary, G., Chafey, P., Camoin, L., Nilges, M., Nassif, X., and Dumenil, G. (2011). Posttranslational modification of pili upon cell contact triggers $N$. meningitidis dissemination. Science 331, 778-782.

Forest, K. T., Dunham, S. A., Koomey, M., and Tainer, J. A. (1999). Crystallographic structure reveals phos- phorylated pilin from Neisseria: phosphoserine sites modify type IV pilus surface chemistry and fibre morphology. Mol. Microbiol. 31, 743-752.

Hegge, F. T., Hitchen, P. G., Aas, F. E., Kristiansen, H., Lovold, C., Egge-Jacobsen, W., Panico, M., Leong, W. Y., Bull, V., Virji, M., Morris, H. R., Dell, A., and Koomey, M. (2004). Unique modifications with phosphocholine and phosphoethanolamine define alternate antigenic forms of Neisseria gonorrhoeae type IV pili. Proc. Natl. Acad. Sci. U.S.A. 101, 10798-10803.

Higashi, D. L., Lee, S. W., Snyder, A., Weyand, N. J., Bakke, A., and So, M. (2007). Dynamics of Neisseria gonorrhoeae attachment: microcolony development, cortical plaque formation, and cytoprotection. Infect. Immun. 75, 4743-4753.

Marceau, M., Beretti, J. L., and Nassif, X. (1995). High adhesiveness of encapsulated Neisseria meningitidis to epithelial cells is associated with the formation of bundles of pili. Mol. Microbiol. 17, 855-863.

Marceau, M., Forest, K., Beretti, J.L., Tainer, J., and Nassif, X. (1998). Consequences of the loss of O-linked glycosylation of meningococcal type IV pilin on piliation and pilus-mediated adhesion. Mol. Microbiol. 27, 705-715.

Stimson, E., Virji, M., Barker, S., Panico, M., Blench, I., Saunders, J., Payne, G., Moxon, E. R., Dell, A., and Morris, H. R. (1996). Discovery of a novel protein modification: alpha- glycerophosphate is a substituent of meningococcal pilin. Biochem. J. 316, 29-33.

Stimson, E., Virji, M., Makepeace, K., Dell, A., Morris, H. R., Payne, G., Saunders, J. R., Jennings, M. P., Barker, S., Panico, M., Blench, I., and Moxon, E. R. (1995). Meningococcal pilin: a glycoprotein substituted with digalactosyl 2,4-diacetamido-2,4,6-trideoxyhexose. Mol. Microbiol. 17, 1201-1214.

Warren, M. J., and Jennings, M. P. (2003). Identification and characterization of pptA: a gene involved in the phase-variable expression of phosphorylcholine on pili of Neisseria meningitidis. Infect. Immun. 71, 6892-6898.

Received: 24 March 2011; accepted: 24 March 2011; published online: 04 April 2011.

Citation: Chen A and Seifert HS (2011) Interactions with host cells causes Neisseria meningitidis pili to become unglued. Front. Microbio. 2:66. doi: 10.3389/ fmicb.2011.00066

This article was submitted to Frontiers in Cellular and Infection Microbiology, a specialty of Frontiers in Microbiology.

Copyright ( $\odot 2011$ Chen and Seifert. This is an open-access article subject to a non-exclusive license between the authors and Frontiers Media SA, which permits use, distribution and reproduction in other forums, provided the original authors and source are credited and other Frontiers conditions are complied with. 